\title{
Prevalence of asthma and atopic symptoms in children aged 5-11years
}

\author{
K A W Karunasekera ${ }^{1}$, K P J Perera ${ }^{2}$, M T P R Perera ${ }^{3}$, J Abeynarayana ${ }^{3}$
}

Sri Lanka Journal of Child Health, 2003; 32: 11-14

(Key words: Prevalence, asthma, atopy, children)

\begin{abstract}
Objective To assess prevalence of asthma and atopic symptoms in a group of school children aged 511 years and to look at prevalence of usage of asthma medications.
\end{abstract}

Setting Three schools in Gampaha District in August 1998.

Method A questionnaire translated into Sinhala was distributed to parents/guardians of 2195 children aged 5-11 years in Grades 1-5 of the schools and the filled questionnaires were collected through class teachers. Asthma, allergic rhinitis and eczema were defined using the clinical criteria of the International Study of Asthma and Allergic Conditions (ISAAC). Data was analysed using Epi Info version 6. Chi squared test and Chi squared test for trend were used for significance testing.

Results Return rate of questionnaire was 93\%. Sixty six percent were completed by mother, $30 \%$ by father and rest by guardian. Prevalence of asthma was $23 \%$ and of exercise induced asthma $11 \%$. Prevalence rate of allergic rhinitis was $10 \%$ and eczema $3 \%$. Within the specific group of asthma, in response to leading question "Has your child had asthma" only $19 \%$ of parents gave a positive answer. Prevalence of asthma in males did not significantly differ from that in females $(p=0.5)$. A decreasing trend of asthma was observed with increasing age in girls $(p<0.05)$. Eighty four percent of asthmatic children were using salbutamol orally and $9 \%$ without asthma in study population were also using salbutamol.

Conclusions One in 5 children aged 5-11 years in study population had asthma but parental perception about asthma was poor. More than $80 \%$ of asthmatics had some medications for the disease.

\footnotetext{
${ }^{1}$ Senior Lecturer, ${ }^{2}$ Lecturer, ${ }^{3}$ Temporary Demonstrator, Department of Paediatrics, Faculty of Medicine, University of Kelaniya.
}

\section{Introduction}

In many parts of the world asthma is the leading cause of chronic illness in childhood. It is also a common cause of school absenteeism ${ }^{1}$. Prevalence of asthma is increasing all over the world ${ }^{2,3}$. However, little is known about the exact prevalence of asthma and atopic conditions in Sri Lanka. This study was undertaken to assess the prevalence of asthma and atopic symptoms in a group of school children aged 5-11 years in the Gampaha District. The study also looked at prevalence of asthma medication usage in the same population.

\section{Method}

The study was carried out in 3 schools in the Gampaha District in August 1998. All were mixed schools situated in semiurban areas. Selection of schools was based on easy accessibility. A selfadministered, purposely designed questionnaire was sent to parents or guardians of all children who were in Grades 1-5 (ages between 5 and 11 years) in these schools. The questionnaire was aimed at screening and identifying children with asthma and atopic conditions in the preceding 12 months. The following questions were asked:

For asthma "Has your child had wheezing or whistling in the chest in the last 12 months?" We also asked a leading question from parents / guardians "Has your child had asthma in the last 12 months?"

For exercise induced asthma "Whether your child developed paroxysms of dry cough / wheezing / became unusually breathless during play, in the last 12 months?"

In addition, we asked whether their children had paroxysms of nocturnal cough, difficulty in breathing, persistence of dry cough for more than a week following a common cold, to try and identify other symptoms of asthma. 
For allergic rhinitis "Has your child had a problem with sneezing with runny nose or blocked nose without having an associated common cold in the last 12 months?"

For eczema "Has your child had an itchy rash which was coming and going in lower limbs in the last 12 months?"

For asthma medication "Has your child used oral salbutamol / inhaler / required nebulization in the last 12 months?"

We requested the class teachers to collect the filled questionnaires within a week after distribution.

The questionnaire was translated into Sinhala using appropriate words. Pilot testing of the translation was performed using in-ward patients in the University Paediatric Unit of Colombo North Teaching Hospital, Ragama and the questionnaire was validated.

Data was analysed using Epi Info version 6. Chi squared test and Chi squared test for trend were used for significance testing.

The Ethics Committee of the Faculty of Medicine, University of Kelaniya, granted ethical clearance for the study.

\section{Results}

Two thousand and forty three (93\%) out of 2195 questionnaires were returned. Of them $66 \%$ were completed by the mother, $30 \%$ by the father and the rest by a guardian. The prevalence of asthma and atopic conditions is given in Table 1.

Table 1

Prevalence of asthma and atopy

\begin{tabular}{|l|c|}
\hline \multicolumn{1}{|c|}{ Condition } & Prevalence (\%) \\
\hline Asthma & $441(23)$ \\
\hline Exercise induced asthma & $225(11)$ \\
\hline Allergic rhinitis & $204(10)$ \\
\hline Eczema & $51(3)$ \\
\hline
\end{tabular}

Total subjects $=2043$

Within the specific group of asthma, in response to the leading question "Has your child had asthma" only $84(19 \%)$ gave a positive answer. Prevalence of asthma in males was $23 \%$, which did not significantly differ from that in females which was $22 \%(\mathrm{p}>0.5)$. Of the group who had exercise induced asthma, 56 $(25 \%)$ children did not have wheezing other than during play. There was a positive family history of atopy (presence of either allergic rhinitis or eczema) in $219(66 \%)$ of asthmatic children in the study.

A significant decrease in trend of asthma prevalence was observed with increasing age in girls as shown in Table $2(\mathrm{p}<0.05)$.

Table 2

Prevalence of asthma in relation to the age

\begin{tabular}{|l|c|c|c|c|c|c|c|}
\hline Gender & \multicolumn{5}{|c|}{ Age in years } & Total & Chi square for \\
trend & P value \\
& $5-6$ & $6.1-8$ & $8.1-10$ & $10.1-11$ & & \\
& $N(\%)$ & $N(\%)$ & $N(\%)$ & $N(\%)$ & & & \\
\hline Male & $21(20)$ & $93(24)$ & $80(24)$ & $20(24)$ & 918 & 0.26 & 0.6 \\
\hline Female & $27(28)$ & $94(24)$ & $77(20)$ & $22(18)$ & 995 & 4.8 & 0.03 \\
\hline
\end{tabular}

The prevalence of other symptoms of asthma is given in Table 3 .

Table 3

Prevalence of other symptoms of asthma in the study population

\begin{tabular}{|l|c|c|c|}
\hline \multicolumn{1}{|c|}{ Symptom } & \multicolumn{2}{|c|}{ Asthma } & P value \\
\hline & Yes & No & \\
& $N(\%)$ & $N(\%)$ & $<0.001$ \\
\hline Paroxysms of cough & $253 / 404(63)$ & $130 / 1476(09)$ & $<0.001$ \\
\hline Difficulty in breathing & $275 / 441(62)$ & $62 / 1510(04)$ & $<0.001$ \\
\hline Persistence of cough after a cold & $288 / 428(67)$ & $197 / 1495(13)$ & \\
\hline
\end{tabular}

The distribution of usage of asthma medication is shown in Figure 1. 


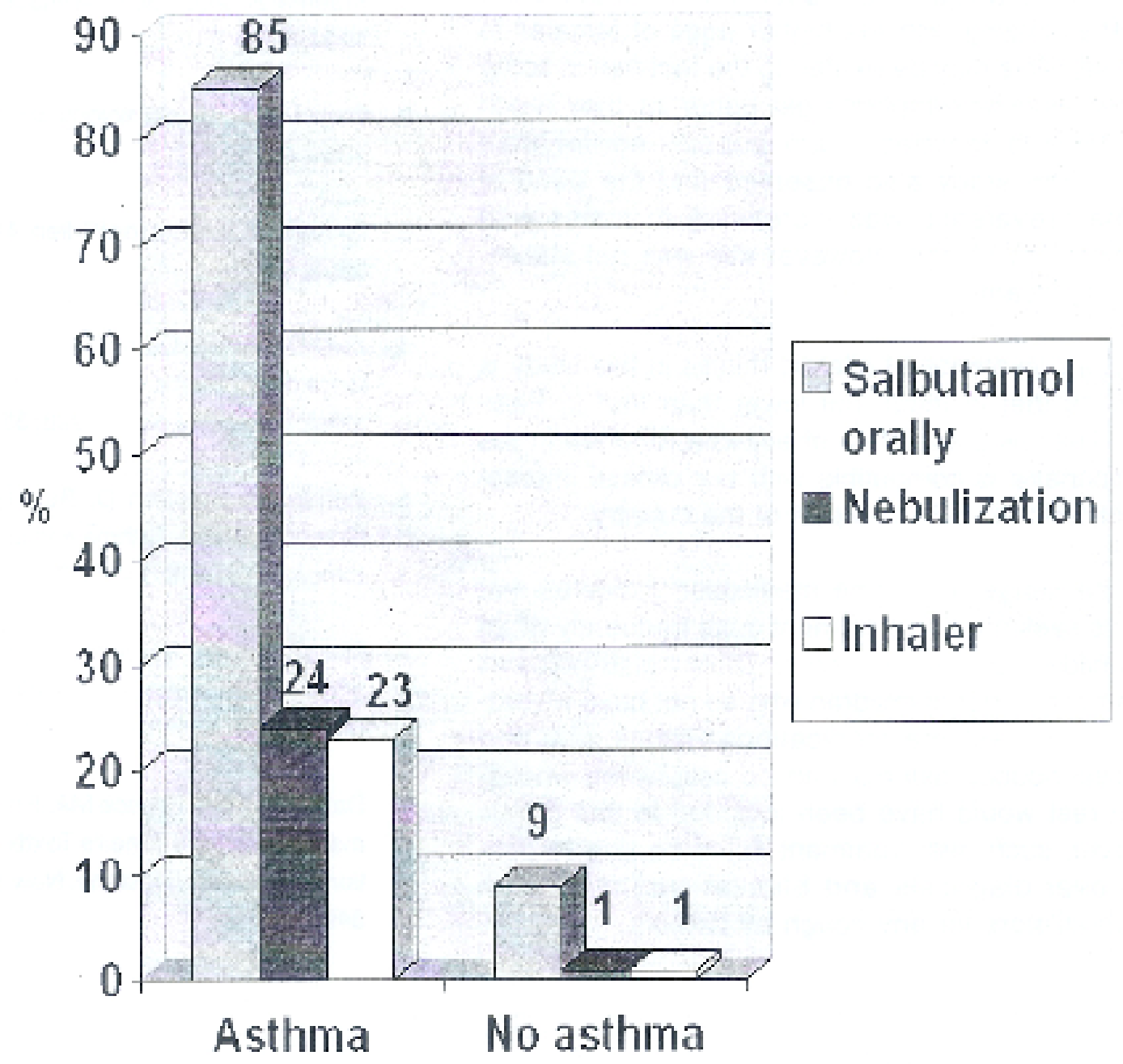

Figure 1. Usage of asthma medication (total subject $=2043$ )

\section{Discussion}

We assessed the prevalence rate of asthma and atopic conditions using the same criteria used by the International Study of Asthma and Allergies of Childhood (ISAAC) ${ }^{4}$. Parental reporting of wheezing in this study is much higher than in some of the other Asian countries such as India, Pakistan and China, but lower than that in the $\mathrm{UK}^{4,5}$. Parental understanding of the symptoms could also have had some effect on the prevalence rates, as the educational level was not homogeneous among parents.

The relatively low level of acceptance of their children having asthma by parents indicates that their perception regarding the illness is sub-optimal.
Furthermore, it is also possible that parents do not want to accept that their children have asthma due to the social and cultural stigmata attached to the illness in this country.

There is a significant reduction in the prevalent rate of wheezing with the higher ages of females in the study. This may be related to the fact that in some children asthma symptoms get better as they reach puberty $^{6}$ and females attain puberty earlier than males $^{7}$. The study also observed that the trend of asthma prevalence was increasing in males with advancement of age. However, this was not statistically significant.

The prevalence of allergic rhinitis in this study is similar to that in India, but lower than that in 
Pakistan ${ }^{4}$. The low prevalence of eczema reported in the questionnaire is compatible with our clinical impression of children from this part of the country.

The usage of asthma medication indicates that parents seek medical treatment quite frequently when their children develop wheezing. Figure 1 also indicates that a fair number of children who do not have wheezing were on asthma medications. Those who had exercise-induced asthma with no associated wheezing at rest would have been included in this group. However, such over-treatment could also be due to possible over-diagnosis and blanket treatment with bronchodilators for any cough by doctors.

\section{Conclusions}

The study shows that one fifth of school children between 5-11 years in the study population had experienced wheezing in the preceding one year. The parental perception about the asthma is poor although a large number of asthmatic children had received treatment.

\section{Acknowledgements}

We thank the children and their families who participated and completed the questionnaires. Without them this study would not have been possible. We also thank the principals of the schools and class teachers of Grades 1-5 for extending their fullest co-operation and support during data collection.

\section{References}

1. Kraemer R. Acute asthma attack in children. Ther-Umsch 1994; 51 (9): 610-5.

2. Cogswell JJ. Epidemiology of asthma Current Paediatrics 1994; 4: 139-42.

3. Le Souef P. Asthma in children. Medicine International 1999; 99 (4); 54-8.

4. ISAAC Steering Committee. Worldwide variation in prevalence of symptoms of asthma, allergic rhinoconjunctivitis and atopic eczema. Lancet 1998; 351: 1225.

5. Prittanji A, Stachan D, Burr M, Sinamati J, Shkurti A, Grabocka E et al. Asthma and allergy in Albania and the UK. Lancet 2001; 358: 1426-7.

6. Mckenzie S, Silverman M. Respiratory disorders. In: Forfar and Arneil Textbook of Paediatrics, $5^{\text {th }}$ ed. London: Churchill Livingstone 1998; 489-583.

7. Dattani MT, Preece MA. Physical growth and development. In: Forfar and Arneil Textbook of Paediatrics, $5^{\text {th }}$ ed. London: Churchill Livingstone 1998; 349-80. 